\title{
Reação de clones de videira a Xanthomonas campestris pv. viticola, baseada nos componentes epidemiológicos do cancro bacteriano
}

\author{
Reaction of grapevine clones to Xanthomonas campestris pv. viticola, based on \\ epidemiological components of bacterial canker
}

\author{
Ana Rosa Peixoto Nascimento ${ }^{1}$ Sami Jorge Michereff ${ }^{2}$ \\ Rosa de Lima Ramos Mariano ${ }^{2}$ Ivanise de Oliveira Viana ${ }^{2}$
}

\section{RESUMO}

O cancro bacteriano, causado por Xanthomonas campestris pv. viticola (Xcv), é a doença bacteriana mais importante da videira na região do Submédio São Francisco. A reação de 20 clones de videira, sendo 13 de copa e sete de porta-enxerto, foi avaliada quanto à resistência ao patógeno, em casa de vegetação. As plantas foram inoculadas com a suspensão do isolado Xcvl $\left(A_{570}=10^{8} \mathrm{UFC} \mathrm{mL}^{-1}\right)$, incubadas em casa de vegetação e observadas diariamente quanto aos componentes epidemiológicos do cancro bacteriano: período de incubação, incidência de folhas com sintomas, incidência de folhas com cancro, severidade da doença, taxa de progresso da incidência da doença, área abaixo da curva de progresso da severidade da doença. Todos os clones foram suscetiveis ao patógeno, embora diferindo significativamente entre si $(P=0,05)$ para a maioria das variáveis analisadas. Em geral, 'Brasil' apresentou os maiores níveis de doença para todas as variáveis testadas, enquanto'Isabel'e 'Paulsen 1103' destacaram-se ao propiciarem os maiores valores de período de incubação e os menores valores de incidência de folhas com sintomas, com cancros, severidade da doença, taxa de progresso de incidência da doença e área abaixo da curva de progresso da severidade da doença, indicando grande potencial de utilização em programas de melhoramento genético e manejo integrado. As correlações significativas $(P=0,05)$ verificadas entre as variáveis estudadas indicam que qualquer delas pode ser utilizada em pesquisas envolvendo reação de clones ao cancro bacteriano da videira. Quando considerado o conjunto dos componentes epidemiológicos, o agrupamento pelo método UPGMA (agrupamento aos pares pela média aritmética não ponderada) permitiu a separação dos clones de copa e porta-enxerto em três grupos de similaridade cada.

Palavras-chave: Vitis spp., resistência genética, incidência, severidade.

\begin{abstract}
Bacterial canker caused by Xanthomonas campestris pv. viticola $(X c v)$ is the most important bacterial disease of grapevine in the region of Submédio São Francisco. The resistance of 20 grapevine clones, 13 scions and seven rootstocks, was evaluated in greenhouse. Plants were inoculated with suspension of the strain Xcv1 $\left(A_{570}=10^{8} \mathrm{CFU} \mathrm{mL}^{-1}\right)$, incubated in greenhouse and daily evaluated for epidemiological components of bacterial canker: incubation period, incidence of leaves with symptoms, incidence of leaves with canker, disease severity, progress rate of disease incidence, and area under the disease severity progress curve. All clones were susceptible to the pathogen, although significantly differing among them $(P=0.05)$ for most of all variables. Generally 'Brasil' showed the highest disease levels for all variables tested while 'Isabel' and 'Paulsen 1103' presented the highest values of incubation period and the lowest values of incidence of leaves with symptoms, with canker, disease severity, progress rate of disease incidence, and area under the disease severity progress curve, suggesting that these clones can be used in breeding and integrated management programs. The significant correlations $(P=0.05)$ among variables indicated anyone could be used to analyze the reaction of grapevine clones to bacterial canker. Considering all the epidemiological components, the grouping according to the UPGMA method (unweighted par group method using arithmetic average) allowed the separation of scion and rootstock clones into three similarity groups each.
\end{abstract}

Key words: Vitis spp., genetic resistance, incidence, severity.

\section{INTRODUÇÃo}

O cultivo da videira (Vitis spp.) na região do Submédio São Francisco tem grande importância socio econômica, pois constitui uma das principais

${ }^{1}$ Departamento de Tecnologia e Ciências Sociais, Universidade do Estado da Bahia, UNEB, Av Edgard Chastnet, s/n, 48900-000, Juazeiro, BA, Brasil.

${ }^{2}$ Departamento de Agronomia,. Universidade Federal Rural de Pernambuco, UFRPE, 52171-030, Recife, PE, Brasil. E-mail: rmariano@truenet.com.br. Autor para correspondência (R.L.R. Mariano). 
culturas para exportação e se destaca, entre as culturas irrigadas, como a mais importante para comercialização no mercado interno (SILVA \& CORREIA, 2000). Entretanto, sua produtividade e qualidade são afetadas por diversos fatores, incluindo a ocorrência de doenças como o cancro bacteriano, causado por Xanthomonas campestris pv. viticola (Nayudu) Dye., que constitui a principal doença bacteriana da videira na região.

Esta doença foi detectada pela primeira vez no Brasil em 1998, em parreirais do Submédio São Francisco, onde tem causado grandes prejuízos em cultivares suscetíveis (LIMA et al., 1999; MALAVOLTA et al., 1999; NASCIMENTO \& MARIANO, 2004). Nas folhas, os sintomas surgem como pontos necróticos de 1 a $2 \mathrm{~mm}$ de diâmetro, com ou sem halos amarelados, podendo coalescer e causar a morte de extensas áreas do limbo foliar. Nas nervuras e pecíolos das folhas, nos ramos e ráquis dos frutos, formam-se manchas escuras e alongadas, que evoluem para fissuras longitudinais de coloração negra conhecidas como cancros. As bagas são desuniformes em tamanho e cor (NAYUDU, 1972), podendo apresentar lesões necróticas. Uma vez que produtos químicos não são eficientes no controle do cancro bacteriano (CHAND, 1989), o uso de cultivares resistentes pode ser uma alternativa de controle (CHAND, 1992), sendo fundamental a análise da reação de clones ao patógeno em condições controladas e no campo. A comparação de epidemias, baseada em componentes epidemiológicos da doença, é um instrumento de pesquisa que permite identificar semelhanças e diferenças, constituindo em importante ferramenta para análise quantitativa da resistência de genótipos às doenças de plantas (KRANZ, 2002).

Reação de clones de videira a $X$. campestris pv. viticola foi estudada na Índia (CHAND, 1992) e no estado de São Paulo, Brasil (MALAVOLTA et al., 2003). Em Pernambuco, diferenças na susceptibilidade de clones de uvas apirênicas ao patógeno foram observadas em campo (LOPES et al., 2004).

O objetivo do estudo foi avaliar a reação de clones de videira quanto à resistência a Xanthomonas campestris pv. viticola, com base nos componentes epidemiológicos da doença, em condições de casa de vegetação, em Recife, Pernambuco.

\section{MATERIAL E MÉTODOS}

Foi utilizado o isolado Xcv1 de $\boldsymbol{X}$. campestris pv. viticola, obtido de ramo de videira, "Red Globe" com sintomas característicos do cancro bacteriano, proveniente do município de Juazeiro, BA. A confirmação da patogenicidade foi realizada em plantas de "Red Globe", com 100 dias de idade. O método de inoculação utilizado foi fricção com gaze.
Compressas de gaze dupla umedecidas com $0,5 \mathrm{~mL}$ da suspensão bacteriana foram levemente friccionadas em ambas as superfícies da folha. A suspensão bacteriana em água destilada esterilizada contendo Tween 20 $(0,05 \%)$ foi ajustada à concentração de $\mathrm{A}_{570}=10^{8}$ unidades formadoras de colônias (UFC) $\mathrm{mL}^{-1}$, conforme equação previamente determinada e inoculada em cinco folhas por planta. As plantas foram submetidas à pré e pós-tratamento em câmara úmida por 48 horas e incubadas em casa de vegetação.

A reação de 20 clones de videira, incluindo de copa e porta-enxerto (Tabela 1), foi avaliada em casa de vegetação em relação a $X$. campestris pv. viticola, baseada nos componentes epidemiológicos do cancro bacteriano. As plantas, com 150 dias, foram fornecidas pela Embrapa Semi-Árido (Petrolina - PE) e mantidas em sacos de polietileno $(14 \mathrm{~cm}$ x $22 \mathrm{~cm})$ contendo vermiculita:solo arenoso (1:9, v:v). Após a inoculação, realizada como no teste de patogenicidade, as plantas foram mantidas em casa de vegetação e irrigadas por rega com mangueira. Durante o experimento, a temperatura e umidade relativa na casa de vegetação foram registradas, calculando-se as médias. O delineamento experimental foi o inteiramente casualizado, com 20 tratamentos e cinco repetições por tratamento, sendo cada repetição constituída por uma planta e cinco folhas avaliadas por planta.

As plantas foram avaliadas diariamente, até 42 dias após a inoculação, determinando-se os seguintes componentes epidemiológicos do cancro bacteriano: a) período de incubação (PI), representado pelo número de dias entre a inoculação e o surgimento dos sintomas da doença. Plantas que não apresentaram sintomas da doença tiveram o período de incubação ajustado para 43 dias, correspondendo ao período de avaliação total acrescido de um dia, conforme proposto por IAMSUPASIT et al. (1993); b) incidência de folhas com sintomas aos 42 dias após a inoculação (INC), calculada pela porcentagem de folhas com sintomas em relação ao total de folhas avaliadas por planta; c) incidência de folhas com cancro aos 42 dias após a inoculação (IFC), calculada pela porcentagem de folhas com cancro em relação ao total de folhas avaliadas; d) severidade da doença aos 42 dias após a inoculação (SEV), estimada com o auxílio de escala diagramática variando de 2 a $91 \%$ de área foliar com sintomas (NASCIMENTO et al., 2005); d) taxa de progresso da incidência da doença (TPID), representada como monit/ dia e estimada pelo parâmetro $b$ da equação de regressão linear simples, tendo a proporção da incidência de folhas doentes linearizada pela transformação monomolecular [ $y=\ln [1 /(1-y)]]$ (CAMPBELL \& MADDEN, 1990) como variável 
Reação de clones de videira a Xanthomonas campestris pv. viticola, baseada nos componentes...

Tabela 1 - Características dos clones de videira (POMMER et al., 2003) avaliados quanto a reação a Xanthomonas campestris pv. viticola, em condições de casa de vegetação, Recife, PE.

\begin{tabular}{|c|c|c|c|}
\hline Clone & Tipo & Coloração da baga & Espécie \\
\hline Benitaka & Copa, com semente & Rosada-escura & Vitis vinifera \\
\hline Brasil & Copa, com semente & Roxa-escura & V. vinifera (mutação somática da uva Benitaka) \\
\hline Cabernet & Copa, com semente & Preta & $V$. vinifera \\
\hline Isabel & Copa, com semente & Preta-azulada & V. labrusca \\
\hline Itália & Copa, com semente & Verde-amarelada & V. vinifera \\
\hline Moscatel & Copa, com semente & Preto-avermelhada & Cruzamento de $\boldsymbol{V}$. labrusca X híbridos com $\boldsymbol{V}$. vinifera \\
\hline Patrícia & Copa, com semente & Preta & Híbrido de IAC de 3 a. geração \\
\hline Petit Sirah & Copa, com semente & Rosada & - \\
\hline Red Globe & Copa, com semente & Rosada & V. vinifera \\
\hline Catalunha & Copa, sem semente & Verde & Variedade não identificada \\
\hline Crimson Seedless & Copa, sem semente & Rosada & - \\
\hline Superior Seedless & Copa, sem semente & Verde & Obtida em programa privado de melhoramento na Califórnia, EUA \\
\hline Thompson Seedless & Copa, sem semente & Verde & Originária da Ásia Menor \\
\hline Courdec 1613 & Porta-enxerto & - & Cruzamento de $\boldsymbol{V}$. berlandieri, V.rupestris e V. riparia \\
\hline Harmony & Porta-enxerto & - & Cruzamento de $V$. riparia, $V$. rupestris, $V$. candicans com $V$. champini \\
\hline IAC 572 & Porta-enxerto & - & Cruzamento de $\boldsymbol{V}$. caribaea e $\boldsymbol{V}$. riparia com $\boldsymbol{V}$. rupestris \\
\hline IAC 766 & Porta-enxerto & - & Cruzamento de $V$. riparia, $V$. rupestris, $V$. cordifolia com $V$. caribaea \\
\hline Paulsen 1103 & Porta-enxerto & - & Cruzamento de $\boldsymbol{V}$. berlandieri, V.rupestris e V.riparia \\
\hline $\mathrm{SO} 4$ & Porta-enxerto & - & Cruzamento de $\boldsymbol{V}$. berlandieri com $\boldsymbol{V}$. riparia \\
\hline $420 \mathrm{~A}$ & Porta-enxerto & - & Cruzamento de $\boldsymbol{V}$. berlandieri com $\boldsymbol{V}$. riparia \\
\hline
\end{tabular}

dependente e o tempo em dias após a inoculação como variável independente. A transformação monomolecular foi utilizada porque propiciou o melhor ajuste das curvas de incidência na maioria das situações quando comparada às demais transformações testadas (exponencial, logística e Gompertz), com base no maior coeficiente de determinação da regressão $\left(\mathrm{R}^{2}\right)$ para reciprocidade entre valores observados e previstos de incidência da doença, menor quadrado médio do resíduo e ausência de tendências indesejáveis no gráfico de dispersão de resíduos, e) área abaixo da curva do progresso da severidade da doença (AACPSD), calculada pela expressão: $\mathrm{AACPSD}=\sum\left(\mathrm{y}_{\mathrm{i}}+\mathrm{y}_{\mathrm{i}+1}\right) / 2 \cdot \mathrm{d}_{\mathrm{ti}}$, onde $\mathrm{y}_{\mathrm{i}}$ e $\mathrm{y}_{\mathrm{i}+1}$ são os valores de severidade observados em duas avaliações consecutivas e $\mathrm{d}_{\mathrm{ti}} \mathrm{O}$ intervalo entre as avaliações (SHANER \& FINNEY, 1977). Nenhuma transformação testada propiciou o ajuste satisfatório das curvas de severidade na maioria das situações, motivo pelo qual foi calculada a AACPSD (CAMPBELL \& MADDEN, 1990).

As análises foram conduzidas em duas etapas: inicialmente, foi realizada a análise univariada, considerando cada variável separadamente. Posteriormente os dados foram submetidos à análise multivariada, considerando as variáveis em conjunto. Para a análise univariada, os dados foram transformados em $\sqrt{x+0,5}$ e submetidos à análise de variância, sendo as médias comparadas pelo teste de agrupamento de Scott-Knott $(\mathrm{P}=0,05)$. Adicionalmente, foi avaliada a correlação entre as variáveis, pela análise de correlação de Pearson $(\mathrm{P}=0,05)$, efetuada com o programa SAEG (Sistema de Análises Estatísticas e Genéticas, Universidade Federal de Viçosa, Viçosa MG, 2003). Considerando o conjunto de variáveis para clones de copa e porta-enxerto - análise multivariada, empregou-se a análise de agrupamento pelo método UPGMA (agrupamento aos pares pela média aritmética não ponderada), com auxílio do programa STATISTICA for Windows (StatSoft Inc., Tulsa - OK, USA, 2000).

\section{RESULTADOS E DISCUSSÃO}

As plantas de todos os clones de videira apresentaram sintomas do cancro bacteriano. Foram constatadas diferenças significativas $(\mathrm{P}=0,05)$ entre os clones quando considerados os diferentes componentes epidemiológicos, sendo que o número de agrupamentos de similaridade variou conforme o componente epidemiológico.

Com relação ao período de incubação, os clones foram distribuídos em dois grupos de similaridade pelo teste de Scott-Knott.

O período de incubação médio para o grupo A, contendo 'Isabel' e 'Paulsen 1103', foi de 39,5 dias, 
enquanto para o grupo $\mathrm{B}$, contendo 18 clones, foi de apenas 11,2 dias. O período de incubação pode demonstrar os diferentes níveis de resistência das plantas, sendo diretamente influenciado pelo genótipo da cultivar, ou seja, cultivares suscetíveis tendem a encurtar este período (KONG et al., 1997), como verificado para os clones de videira incluídos no grupo A. Diferenças no período de incubação refletem diferenças na taxa de crescimento do patógeno no hospedeiro, e, conseqüentemente, na taxa de progresso da epidemia, sendo um importante componente de resistência (PARLEVLIET, 1979). Entretanto, o período de incubação pode sofrer influências de fatores como temperatura, umidade do ar, idade da planta e concentração de inóculo do patógeno (KONG et al., 1997).

Os reduzidos períodos de incubação observados, na maioria dos clones, indicam que o método de inoculação utilizado foi eficiente, que as condições de temperatura $\left(28,5 \pm 5^{\circ} \mathrm{C}\right)$ e umidade relativa do $\operatorname{ar}(75,4 \pm 6 \%)$ na casa de vegetação foram favoráveis ao desenvolvimento da doença e que os clones apresentaram elevada sensibilidade ao patógeno. Esses resultados assemelham-se aos constatados por LIMA et al. (1999), que observaram PI de 12 a 14 dias em 'Red Globe' e por NAYUDU (1972) que constatou PI de 6 dias em 'Anab-e-Shahi'. Essa variação no tempo de aparecimento dos sintomas pode estar relacionada às diferenças nas constituições genotípicas dos materiais utilizados e nos métodos de inoculação empregados, uma vez que as condições de incubação das plantas inoculadas (temperatura e umidade) foram similares em todos os estudos.

Quando considerada a incidência de folhas com sintomas, 17 clones de videira apresentaram valores iguais ou superiores a $80 \%$, sendo incluídos no grupo A (Tabela 2). O grupo B incluiu os clones Paulsen 1103 (8\%), Isabel (40\%) e SO4 (52\%), que apresentaram níveis significativamente inferiores de incidência de folhas com sintomas.

A incidência de folhas com cancro variou de 0 a $72 \%$ (Tabela 2). Os maiores valores foram observados nos clones Benitaka, Brasil, Cabernet, Red Globe, Catalunha, Thompson Seedless e $420 \mathrm{~A}$, que não diferiram significativamente entre si, indicando que nestes materiais a bactéria colonizou rapidamente os vasos condutores, demonstrando alta susceptibilidade ao patógeno. Por outro lado, não foram observados cancros nas nervuras das folhas de 'Paulsen 1103', evidenciando elevada resistência à colonização.

A severidade do cancro bacteriano, aos 42 dias após a inoculação, variou de 0,08 a 23,24\% e os clones foram distribuídos em quatro grupos de similaridade (Tabela 2). O grupo A incluiu os clones Benitaka, Brasil, Catalunha e Thompson Seedless, que apresentaram elevada severidade da doença, diferindo significativamente dos demais. Os clones dos grupos B e C apresentaram severidades variando de $4,48 \%$ a 9,14\% e de 2,27\% a 3,70\%. O grupo D incluiu 'Paulsen 1103 ' e 'Isabel', que apresentaram menor severidade. 'Paulsen 1103' é um porta-enxerto resultante do cruzamento de $\boldsymbol{V}$. berlandieri Planchon, $\boldsymbol{V}$. rupestris Scheele e $\boldsymbol{V}$. riparia Michaux e 'Isabel' pertence à espécie V. labrusca L. Estes resultados assemelhamse aos constatados por CHAND (1992), que testou 14 espécies de Vitis, sete outras vitáceas e 73 cultivares de $\boldsymbol{V}$. vinifera em relação ao cancro bacteriano. Este autor verificou que, entre as espécies de Vitis analisadas, $\boldsymbol{V}$. vinifera foi altamente suscetível, Vitis labrusca se mostrou resistente (em condições de campo) ou moderadamente resistente (sob inoculação artificial), $\boldsymbol{V}$. rupestris e $\boldsymbol{V}$. berlandieri foram resistentes e $\boldsymbol{V}$. riparia altamente resistente. MALAVOLTA et al. (2003) também observaram elevada severidade do cancro bacteriano nos clones Red Globe, Itália, Benitaka e Rubi, todas pertencentes à espécie $\boldsymbol{V}$. vinifera. Já nos clones Niágara branca (hibridação entre V. labrusca e $\boldsymbol{V}$. vinifera) e Niágara rosada (mutação natural de Niágara branca), os autores observaram baixos níveis de severidade da doença, supondo que a resistência destes híbridos tenha vindo de V. labrusca, cujo genótipo deve conter os genes para esta característica.

A taxa de progresso de incidência da doença variou entre os clones de $<0,0001$ a 0,0062monit dia ${ }^{-1}$ (Tabela 2), sendo a maior taxa constatada no clone Brasil, que diferiu significativamente dos demais. 'Isabel' e 'Paulsen 1103' apresentaram taxas inferiores a 0,0001 monit/dia, mas não diferiram significativamente de outros 14 clones, todos incluídos no mesmo grupo de similaridade.

Os valores da área abaixo da curva do progresso da severidade da doença variaram de 0,96 a 477,04, indicando diferenças em susceptibilidade entre os clones (Tabela 2). 'Brasil' apresentou o valor mais elevado, constituindo isoladamente o grupo A, enquanto os menores valores foram apresentados por 'Paulsen 1103' e 'Isabel', que formaram o grupo de similaridade D.

Ciência Rural, v.36, n.1, jan-fev, 2006. 
Tabela 2 - Reação de clones de videira a Xanthomonas campestris pv. viticola, baseada nos componentes epidemiológicos do cancro bacteriano, em condições de casa de vegetação, Recife, PE.

\begin{tabular}{|c|c|c|c|c|c|c|c|}
\hline Tipo & Clone & $\mathrm{PI}(\mathrm{dias})^{1}$ & $\operatorname{INC}(\%)^{2}$ & $\operatorname{IFC}(\%)^{3}$ & $\operatorname{SEV}(\%)^{4}$ & $\underset{(\text { monit/dia })^{5}}{\text { TPID }}$ & AACPSD $^{6}$ \\
\hline \multirow{9}{*}{ 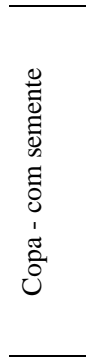 } & Benitaka & $8,00 \mathrm{~b}^{7}$ & $100,00 \mathrm{a}$ & $64,00 \mathrm{a}$ & $15,20 \mathrm{a}$ & $0,0038 \mathrm{~b}$ & $281,22 b$ \\
\hline & Brasil & $8,00 \mathrm{~b}$ & $100,00 \mathrm{a}$ & $72,00 \mathrm{a}$ & $23,24 \mathrm{a}$ & $0,0062 \mathrm{a}$ & $477,04 \mathrm{a}$ \\
\hline & Cabernet & $9,60 \mathrm{~b}$ & $84,00 \mathrm{a}$ & $44,00 \mathrm{~b}$ & $4,48 \mathrm{~b}$ & $0,0008 \mathrm{c}$ & $83,76 \mathrm{c}$ \\
\hline & Isabel & $37,40 \mathrm{a}$ & $40,00 \mathrm{~b}$ & $20,00 \mathrm{~b}$ & $0,28 \mathrm{~d}$ & $<0,0001 \mathrm{c}$ & $2,18 \mathrm{~d}$ \\
\hline & Itália & $9,40 \mathrm{~b}$ & $100,00 \mathrm{a}$ & $32,00 \mathrm{~b}$ & $8,60 \mathrm{~b}$ & $0,0016 \mathrm{c}$ & $144,74 \mathrm{c}$ \\
\hline & Moscatel & $8,00 \mathrm{~b}$ & 88,00 a & $28,00 \mathrm{~b}$ & $8,52 \mathrm{~b}$ & $0,0020 \mathrm{c}$ & $145,38 \mathrm{c}$ \\
\hline & Patrícia & $9,60 \mathrm{~b}$ & 92,00 a & $28,00 \mathrm{~b}$ & $6,54 \mathrm{~b}$ & $0,0012 \mathrm{c}$ & $133,27 \mathrm{c}$ \\
\hline & Petit Sirah & $10,80 \mathrm{~b}$ & 84,00 a & $20,00 \mathrm{~b}$ & $3,70 \mathrm{c}$ & $0,0010 \mathrm{c}$ & $76,48 \mathrm{c}$ \\
\hline & Red Globe & $9,40 \mathrm{~b}$ & $100,00 \mathrm{a}$ & $52,00 \mathrm{a}$ & $9,14 \mathrm{~b}$ & $0,0022 \mathrm{c}$ & $182,61 \mathrm{~b}$ \\
\hline \multirow{4}{*}{ 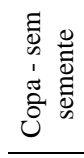 } & Catalunha & $9,40 \mathrm{~b}$ & $100,00 \mathrm{a}$ & 56,00 a & $14,44 \mathrm{a}$ & $0,0032 \mathrm{~b}$ & $221,49 \mathrm{~b}$ \\
\hline & Crimson Seedless & $11,00 \mathrm{~b}$ & 84,00 a & $32,00 \mathrm{~b}$ & $4,82 \mathrm{~b}$ & $0,0010 \mathrm{c}$ & $93,14 \mathrm{c}$ \\
\hline & Superior Seedless & $21,40 \mathrm{~b}$ & 80,00 a & $24,00 \mathrm{~b}$ & $5,14 \mathrm{~b}$ & $0,0012 \mathrm{c}$ & $64,62 \mathrm{c}$ \\
\hline & Thompson Seedless & $8,00 \mathrm{~b}$ & $100,00 \mathrm{a}$ & $72,00 \mathrm{a}$ & $17,80 \mathrm{a}$ & $0,0046 \mathrm{~b}$ & $269,41 \mathrm{~b}$ \\
\hline \multirow{8}{*}{ 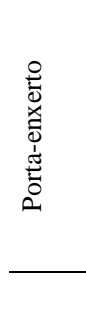 } & Courdec 1613 & $12,60 \mathrm{~b}$ & $92,00 \mathrm{a}$ & $44,00 \mathrm{~b}$ & $3,28 \mathrm{c}$ & $0,0010 \mathrm{c}$ & $66,26 \mathrm{c}$ \\
\hline & Harmony & $16,80 \mathrm{~b}$ & 80,00 a & $40,00 \mathrm{~b}$ & $6,10 \mathrm{~b}$ & $0,0016 \mathrm{c}$ & $110,48 \mathrm{c}$ \\
\hline & IAC 572 & $12,20 \mathrm{~b}$ & 96,00 a & $28,00 \mathrm{~b}$ & $6,18 b$ & $0,0014 \mathrm{c}$ & $118,48 \mathrm{c}$ \\
\hline & IAC 766 & $9,40 \mathrm{~b}$ & 80,00 a & $24,00 \mathrm{~b}$ & $2,56 \mathrm{c}$ & $0,0004 \mathrm{c}$ & $58,62 \mathrm{c}$ \\
\hline & Paulsen 1103 & $41,60 \mathrm{a}$ & $8,00 \mathrm{~b}$ & $0,00 \mathrm{~b}$ & $0,08 \mathrm{~d}$ & $<0,0001 \mathrm{c}$ & $0,96 \mathrm{~d}$ \\
\hline & $\mathrm{SO} 4$ & $13,60 \mathrm{~b}$ & $52,00 \mathrm{~b}$ & $24,00 \mathrm{~b}$ & $2,27 \mathrm{c}$ & $0,0002 \mathrm{c}$ & $36,56 \mathrm{c}$ \\
\hline & $420 \mathrm{~A}$ & $14,00 \mathrm{~b}$ & $100,00 \mathrm{a}$ & 56,00 a & $7,20 \mathrm{~b}$ & $0,0016 \mathrm{c}$ & $113,44 \mathrm{c}$ \\
\hline & C. V. (\%) & 18,18 & 10,18 & 46,35 & 22,08 & 0,12 & 27,20 \\
\hline
\end{tabular}

${ }^{1}$ Período de incubação, representado pelo tempo entre a inoculação e o aparecimento dos sintomas. Plantas que não apresentaram sintomas da doença tiveram o período de incubação ajustado para 43 dias, correspondendo ao período de avaliação total acrescido de um dia (IAMSUPASIT et al., 1993).

${ }^{2}$ Incidência de folhas com sintomas da doença, aos 42 dias após a inoculação do patógeno.

${ }^{3}$ Incidência de folhas com cancro, aos 42 dias após a inoculação do patógeno.

${ }^{4}$ Severidade da doença aos 42 dias após a inoculação, estimada com o auxílio de escala diagramática variando de 2 a $91 \%$ de área foliar com sintomas (NASCIMENTO et al., 2005).

${ }^{5}$ Taxa de progresso da incidência da doença, estimada pelo parâmetro $b$ da equação de regressão linear simples, tendo a proporção da incidência de folhas doentes linearizada pela transformação monomolecular $[y=\ln [1 /(1-y)]]$ (CAMPBELL \& MADDEN, 1990) como variável dependente e o tempo em dias após a inoculação como variável independente.

${ }^{6}$ Área abaixo da curva do progresso da severidade da doença, calculada conforme SHANER \& FINNEY (1977).

${ }^{7}$ Dados originais. Para efeito de análise, todos os dados foram transformados em $\sqrt{x+0,5}$. Médias seguidas da mesma letra na coluna não diferem significativamente $(\mathrm{P}=0,05)$ entre si pelo teste de Scott-Knott.

Foram constatadas correlações significativas $(\mathrm{P}=0,05)$ entre as variáveis $\mathrm{PI}, \mathrm{INC}, \mathrm{IFC}$, SEV, TPID e AACPSD (Tabela 3), demonstrando que qualquer uma pode ser utilizada em pesquisas envolvendo reação de cultivares ao cancro bacteriano da videira. No entanto, a avaliação da severidade aos 42 dias, com o auxílio da escala diagramática, propiciou níveis elevados de correlação com as demais variáveis, além de elevada precisão, acurácia e repetibilidade nas estimativas (NASCIMENTO et al., 2005).

Com base no conjunto dos componentes epidemiológicos do cancro bacteriano da videira, a análise de agrupamento por UPGMA permitiu a distinção de três grupos de similaridade entre os clones de copa e porta-enxerto, quando considerado $50 \%$ da distância total verificada (Figura 1). Entre os clones de copa, um grupo foi formado somente por 'Brasil', um segundo grupo por 'Isabel', e os demais clones constituíram o terceiro grupo de similaridade. Para os clones de porta-enxerto, um grupo foi formado somente por 'Paulsen 1103', um segundo grupo por ' $\mathrm{SO}_{4}$ ' e os demais clones constituíram o terceiro grupo de similaridade. Esses resultados confirmam a existência de variabilidade entre os clones, tanto de copa como porta-enxerto, quanto à sensibilidade a $X$. campestris pv. viticola, considerando os componentes epidemiológicos da doença.

Os clones de $\boldsymbol{V}$. vinifera foram muito suscetíveis ao patógeno. 'Brasil' apresentou os maiores 
Tabela 3 - Coeficientes de correlações entre os componentes epidemiológicos do cancro bacteriano da videira em condições de casa de vegetação: período de incubação (PI), incidência de folhas com sintomas (INC), incidência de folhas com cancro (IFC), severidade aos 42 dias (SEV), taxa de progresso de incidência da doença (TPID) e área abaixo da curva do progresso da severidade da doença (AACPSD).

\begin{tabular}{llllll}
\hline & INC & IFC & SEV & TPID & AACPSD \\
\hline PI & $0,88^{*}$ & $-0,59^{*}$ & $-0,54^{*}$ & $-0,49^{*}$ & $-0,54^{*}$ \\
INC & - & $0,72^{*}$ & $0,63^{*}$ & $0,59^{*}$ & $0,61^{*}$ \\
IFC & & - & $0,85^{*}$ & $0,85^{*}$ & $0,82^{*}$ \\
SEV & & & - & $0,99 *$ & $0,98^{*}$ \\
TPID & & & & - & $0,98^{*}$ \\
\hline
\end{tabular}

*Coeficientes de correlação de Pearson significativos a 5\% de probabilidade.

níveis de doença, enquanto 'Isabel' e 'Paulsen 1103' apresentaram reduzidos níveis de doença indicando grande potencial de utilização em programas de melhoramento genético e manejo integrado. No entanto, apesar de 'Isabel' ser a uva de mesa mais cultivada no Brasil, não é plantada em grande escala no Submédio São Francisco, e 'Paulsen 1103', por ser porta-enxerto, só poderá ser utilizado como tal. Testes adicionais devem ser realizados para observação do comportamento destes clones sob infecção natural em campo, bem como outras espécies de Vitis devem ser incluídas.

\section{AGRADECIMENTOS}

Os autores expressam agradecimentos à Dra. Patrícia Coelho de Souza Leão, da Embrapa Semi-Árido (Petrolina, PE), pela concessão das mudas de videira; ao Engenheiro Agrônomo Gleydson Silva Castro Sousa, pela colaboração na execução do trabalho e à Fundação de Amparo à Pesquisa do Estado da Bahia (FAPESB), pelo apoio financeiro.

Ao Conselho Nacional de Desenvolvimento Científico e Tecnológico (CNPq), pelas bolsas de Produtividade em Pesquisa dos autores Sami Jorge Michereff e Rosa de Lima Ramos Mariano.

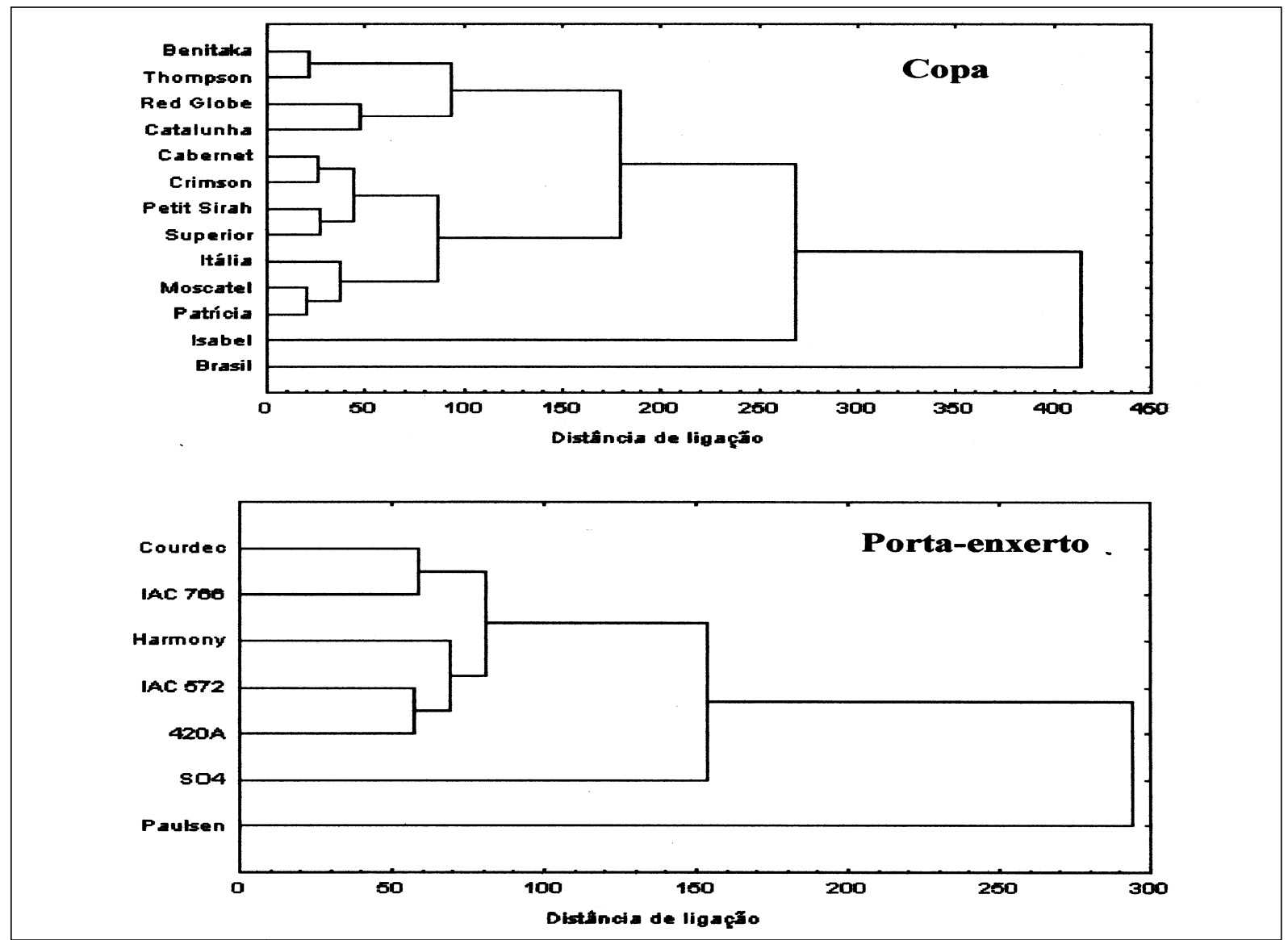

Figura 1- Agrupamento de 13 variedades de copa e 7 variedades de porta-enxerto de videira, baseado no método UPGMA, considerando os componentes epidemiológicos do cancro bacteriano: período de incubação, incidência de folhas com sintomas, incidência de folhas com cancro, severidade da doença aos 42 dias, taxa de progresso de incidência da doença e área abaixo da curva do progresso da severidade da doença.

Ciência Rural, v.36, n.1, jan-fev, 2006. 


\section{REFERÊNCIAS}

CAMPBELL, C.L.; MADDEN, L.V. Introduction to plant disease epidemiology. New York: Jonh Wiley \& Sons, 1990. $532 \mathrm{p}$.

CHAND, R. Grapevine bacterial canker disease and its management. Drakshavritta Souvenir, Pune, v.6, p.74-78, 1989.

CHAND, R. Sources of resistance to grapevine bacterial canker disease in Vitis. Indian Institute of Horticultural Research, Bangalore, v.31, p.83-86, 1992.

IAMSUPASIT, N. et al. Components of quantitative resistance to anthracnose (Colletotrichum gloeosporioides) in tetraploid accessions of the pasture legume Stylosanthes hamata. Australian Journal of Experimental Agriculture, Sydney, v.33, p.855-860, 1993.

KONG, G.A. et al. Components of quantitative resistance in sunflower to Alternaria helianthi. Annals of Applied Biology, London, v.130, p.439-451, 1997.

KRANZ, J. Comparative epidemiology of plant diseases. Berlin: Springer-Verlag, 2002. 206p.

LIMA, M.F. et al. Bacterial canker of grapevine in Brazil. Fitopatologia Brasileira, Brasília, v.24, n.3, p.440-443, 1999.

LOPES, D.B. et al. Ocorrência de cancro bacteriano em cinco variedades de uvas apirênicas. Fitopatologia Brasileira Brasília, v.29, Suplemento, p.S60, 2004.

MALAVOLTA JR., V.A. et al. Ocorrência de Xanthomonas campestris pv. viticola em videira no Brasil. Summa Phytopathologica, Jaboticabal, v.25, n.3, p.262-264, 1999.
MALAVOLTA JR., V.A et al. Resistência de variedades de videira a Xanthomonas campestris pv. viticola. Arquivos do Instituto Biológico, São Paulo, v.70, n.3, p.373-376, 2003.

NASCIMENTO, A.R.P.; MARIANO, R.L.R. Cancro bacteriano da videira: etiologia, epidemiologia e medidas de controle. Ciência Rural, Santa Maria, v.34, n.1, p.301-307, 2004.

NASCIMENTO, A.R.P. et al. Elaboração e validação de escala diagramática para cancro bacteriano da videira. Summa Phytopathologica, Botucatu, v.31, n.1, p.56-61, 2005.

NAYUDU, M.V. Pseudomonas viticola sp. nov., incitant of a new bacterial disease of grape vine. Phytopathologische Zeitschrift, Berlin, v.73, p.183-186, 1972.

PARLEVLIET, J.E. Components of resistance that reduce the rate of epidemic development. Annual Review of Phytopathology, Palo Alto, v.17, p.203-222, 1979.

POMMER, C.V. et al. Cultivares, melhoramento e fisiologia. In: POMMER, C.V. (Ed). Uva: tecnologia de produção, pós-colheita, mercado. Porto Alegre: Cinco Continentes, 2003. p.109-294.

SHANER, G.; FINNEY, R.E. The effect of nitrogen fertilization on the expression of slow-mildewing resistance in knox wheat. Phytopathology, St. Paul, v.67, n.8, p.1051-1056, 1977.

SILVA, P.C.G.; CORREIA, R.C. Caracterização social e econômica da videira. In: SOUZA LEÃO, P.C.; SOARES, J.M. (Eds). A viticultura no semi-árido brasileiro. Petrolina: Embrapa Semi-Árido, 2000. p.19-32. 